Session 2558

\title{
Defining the IT Curriculum: The Results of the Past 21/2 Years
}

\author{
Barry M. Lunt, Joseph J. Ekstrom, Edith A. Lawson, Reza Kamali, Jacob \\ Miller, Sandra Gorka, Han Reichgelt, \\ Brigham Young University/ Brigham Young University/ Rochester Institute \\ of Technology/Purdue University-Calumet/ Pennsylvania College of \\ Technology/ Georgia Southern University
}

\begin{abstract}
Efforts to define IT curriculum and accreditation standards began at the first Conference on Information Technology Curriculum (CITC-1) in December 2001, which included representatives from 15 Information Technology (IT) programs at four-year schools in the United States. Also in attendance were representatives from the Association for Computing Machinery (ACM), the Institute for Electrical and Electronic Engineers (IEEE), and the Accreditation Board for Engineering and Technology (ABET). Much foundational work began at this conference, and committees were formed to continue the work. This work has been ongoing since this first CITC conference, continuing at CITC-2 (April 2002), CITC-3 (September 2002), and CITC-4 (October 2003), and through committee work which has progressed between these conferences. The three main thrusts of this work have been to define standards for accreditation of IT programs, to define a model curriculum for IT programs, and to distinguish IT programs from the most closely-related academic programs, such as Information Systems and Computer Science.

Membership in SIGITE (Special Interest Group on Information Technology Education) of the ACM is now over 100 members and represents most 4-year IT programs and several 2-year IT programs in the United States. Because of the wide representation in SIGITE, it is felt that the outcome of these three main thrusts is of wide interest to all those in related programs or at institutions considering forming a similar program. This paper gives some of the details of the results of the work on these three thrusts.

Introduction and Historical Background

In the first week of December of 2001 representatives from 15 undergraduate information technology (IT) programs from colleges/universities across the country gathered together in Aspen Grove, Utah, to develop a community and begin to establish academic standards for this rapidly growing discipline. The first Conference on Information Technology Curriculum (CITC1) was also attended by representatives from two professional societies, the Association for Computing Machine (ACM) and the Institute of Electrical and Electronics Engineers, Inc. (IEEE), and also the Accreditation Board for Engineering and Technology, Inc. (ABET). This invitational conference was the culmination of an effort begun several months earlier by five of
\end{abstract}


these universities who had formed a steering committee to organize a response from existing IT programs to several initiatives to define the academic discipline of IT. The steering committee wanted to ensure that the input of existing programs played a significant role in the definition of the field.

A formal society and three main committees were formed by the attendees of CITC-1. The society was the Society for Information Technology Education (SITE); one of the committees formed was the executive board for SITE, composed of a president, vice-president, secretary, treasurer, regional representatives, and an activities chairperson. The other two committees formed were the IT Curriculum Committee, including subcommittees for 4-year and 2-year programs, and the IT Accreditation Committee, also including subcommittees for 4-year and 2year programs.

The development of IT as an academic discipline is similar to the process that computer science (CS) went through in the 70's and 80's. In fact, looking at the placement of CS programs in academic institutions around the U.S. illustrates the debate that swirled around the discipline as its core was being defined. Some CS programs are in departments of mathematics, others are in engineering schools, and many others have become freestanding programs within newly emerging colleges of computing.

Information technology, as it is practiced at this moment in its evolution, reflects similar growing pains. IT programs exist in colleges of computing, in CS departments, in schools of technology, and in business schools. Professors of information technology possess degrees in information systems, electronics, communications, graphics arts, economics, mathematics, computer science, and other disciplines. Few to none of them have a degree in information technology.

\section{Procedure for Deciding on an IT Curriculum}

The participants of CITC-1 participated in a Delphi study. A Delphi study is characterized by questions being asked of experts, who then respond freely to them. Their responses to the questions are shared with other experts, who then may modify their previous responses as they

feel necessary. This sharing repeats until the opinions of the experts appear to be converging. 1,2 , $3,4,5$

The format of the Delphi study was much aided by the fact that the relevant experts (the conference attendees) were all co-located. Each participant was issued a pad of self-adhesive sticky notes and a blunt felt-tip marker. Then the entire group was given 20 minutes to generate as many topics as they could, one topic per sticky note. As each participant created a small pile of topics, they were encouraged to spread them out on several tables that were at the front of the room. This way, each participant could see ideas from other participants, further spurring ideas of their own. At the end of the 20 minutes, everyone had pretty well exhausted their ideas, and nearly 700 sticky notes had ideas for topics in an IT curriculum.

The second stage of the exercise was an unconstrained organization of the topics into groups. All attendees participated in moving the notes into groups, and after about 30 more minutes, essentially everyone agreed that all notes in each group belonged there. After this was 
completed, the sticky notes were gathered in their groups, and a spreadsheet was filled out with one column for each group.

After some additional organization of the topics in the categories, the entire output was reduced to 34 topic areas. Some of the topic areas were later found to be so closely related as to be basically inseparable, so they were combined.

At the conclusion of this editing work (about 2 weeks after the conference), the entire edited spreadsheet was sent to all conference attendees via email, and further feedback was sought and incorporated.

Additionally, many of the participating institutions conducted similar Delphi studies with their Industry Advisory Board (IAB) members. IABs are made up of practicing professionals with ties to the academic institution. Through these additional studies, much information was gained from practicing IT professionals, and their input was folded into the work of the IT curriculum committee through the members of that committee.

Results of the Curriculum Development Procedure

The results of these Delphi studies were very significant in several ways: 1) representatives from 15 universities with 4-year IT programs had participated - this represents a significant portion of the programs in the nation; 2) representatives from three professional organizations were also in attendance - these were three of the most relevant; 3) representatives from several institutions' IABs were involved and provided valuable input; and 4) each participant had ample opportunity to share all their thoughts, both as to topics and as to organization, and to get feedback from other participants. 


\begin{tabular}{|l|l|}
\hline$\#$ & \multicolumn{1}{|c|}{ Topic Area } \\
\hline 1 & Networking \\
\hline 2 & Human communications \\
\hline 3 & Software \\
\hline 4 & Web system design \\
\hline 5 & Database \\
\hline 6 & Project management \\
\hline 7 & Digital communications \\
\hline 8 & Data security/privacy \\
\hline 9 & Math \\
\hline 10 & Systems design \\
\hline 11 & Hardware: architecture \& circuits \\
\hline 12 & Human-computer interfacing \\
\hline 13 & User advocacy \\
\hline 14 & Thinking/problem solving \\
\hline 15 & Teamwork \\
\hline 16 & Enterprise topics \\
\hline 17 & Ethics \\
\hline 18 & Embedded systems \\
\hline 19 & Holistic \\
\hline 20 & Information content \\
\hline 21 & Social factors \\
\hline 22 & System administration \\
\hline 23 & General education \\
\hline 24 & Evaluation \\
\hline 25 & Physics \\
\hline 26 & Graphics \\
\hline 27 & Co-ops \\
\hline
\end{tabular}

Table 1: Topic areas in an IT curriculum
Table 1 presents an overview of the results. There are 27 topical areas in this overview, shown in the table in the order of how often they were mentioned. It should be mentioned that there was a great deal of consensus experienced in the many Delphi studies that were conducted, lending further validity to the results.

Another way to look at the results of these studies is to organize the topic areas into four categories typical in most curricula: General education, Related courses, Professional courses, and Core courses. Table 2 gives one way of doing this.

In each column, the ranking is determined by the number of times that topic area came up in the studies. Table 2 gives some powerful insight into one way of defining an IT curriculum for all IT programs across the nation. The topic areas with high rankings indicates a strong number of mentions for the Core Courses, and indicates to these authors that all IT programs should consist of at least one course in at least the top 4 of these areas. It is these topics, in combination, that define the domain of Information Technology. These topic areas are: networking, software, web systems design, and databases. Later the committee agreed to include the topic area of human-computer interaction (HCI) as a fifth defining topic area.

\begin{tabular}{|l|l|l|l|l|}
\hline Ranking & \multicolumn{1}{|c|}{$\begin{array}{c}\text { General } \\
\text { Education }\end{array}$} & \multicolumn{1}{|c|}{$\begin{array}{c}\text { Professional } \\
\text { Courses }\end{array}$} & \multicolumn{1}{c|}{ Core Courses } \\
\hline 1 & Math & Hardware: arch. \& cir. & Human communications & Networking \\
\hline 2 & Holistic & Thinking/prob. solv. & Project management & Software \\
\hline 3 & General education & Embedded systems & Teamwork & Web systems design \\
\hline 4 & Physics & Information content & Enterprise topics & Database \\
\hline 5 & & System administration & Ethics & Digital communication \\
\hline 6 & & Evaluation & Social factors & Data security/privacy \\
\hline 7 & & Graphics & Co-ops & Systems design \\
\hline 8 & & & & Human-computer interaction \\
\hline 9 & & & & User advocacy \\
\hline
\end{tabular}

Table 2: Organizing the main topic areas into four categories of course offering 
After the Core Courses, IT programs could select from the Professional Courses and Related Courses to give their program the unique emphasis they feel is most important for their customers. This would give many strong IT programs across the country, each with a common IT core and an additional focus or flavor unique to each institution.

Most university majors also have sub-specializations within the major. Table 2 can also be used to help define these possible emphases for each IT program.

Finally, Table 2 shows that there is a strong need for a math foundation, particularly in algebra and discrete math. Also, depending on the institutional flavor, there may be a need for a course in physics.

\section{Job Descriptions - An Additional Part of Defining IT}

One of the next steps taken by the IT curriculum committee was to develop a list of the job titles we felt our students should be able to fill. Where the previous curriculum definition work was done from the program definition perspective, this job title list was to be done from the perspective of the desired end product of an IT program.

Members of the IT curriculum committee were asked to provide as many job titles as they could. These job titles were then shared with all members, and further input was sought. After a couple of iterations of this process, the final list was broken into four main categories: networking; information services and support; programming and software development; and interactive media. A full listing of all the job titles described for IT graduates is found in the first part of the Appendix.

\section{Differentiating from Related Disciplines - A Key Part of Defining IT}

In a paper published in the proceedings of CITC- $3^{6}$, and later refined and published in the proceedings of CIEC-2003 ${ }^{7}$, Lunt et al. helped a great deal in defining the academic discipline of information technology, especially with relation to its most closely related disciplines of computer science (CS) and information systems (IS). The study included other related disciplines such as information science, electrical engineering, electronic/telecommunications engineering technology, and computer engineering/engineering technology, and was conducted at 12 institutions which had programs in IT and at least two other related disciplines. A full listing of the institutions included in the study is contained in the second part of the Appendix.

The study consisted of counting the semester credit hours required to graduate in each discipline, and categorizing these requirements into the general areas of business; electronics \& signals; hardware; interpersonal communications; networking, web systems, databases; physics, math, chemistry; and software. Figure 1 below summarizes this information for all the disciplines studied.

For IT, the two most closely-related disciplines are CS and IS. Figures 2, 3 and 4 below provide an excellent comparison of these three academic disciplines, as described in the study cited. It can be seen from Figures 2, 3 and 4 that the dominant category for CS is software, as would be 
expected. The dominant category for IS is business. The dominant area for IT is N,W,D (networks, web systems, and databases).

Knowledge Areas for IT - The CC2001 Document

The CC2001 (Computing Curriculum) document was officially accepted as the model (see www.computer.org/education/cc2001/final/index.htm) toward which we would be working. The CC2001 document was written for computer science, and was structured as one volume of a

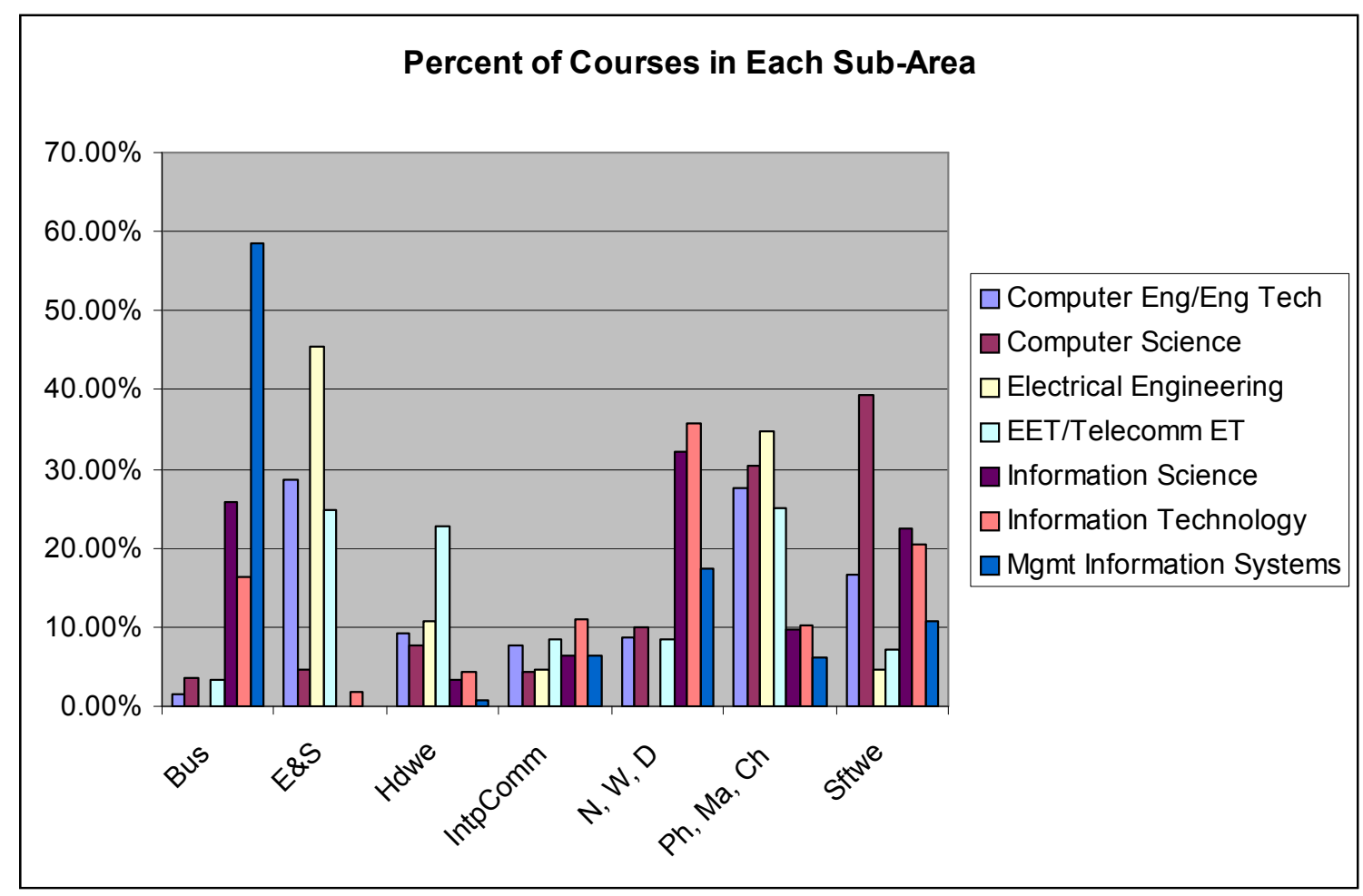

Figure 1: Summary of requirements for all 7 disciplines studied, organized into the categories of Business (Bus); Electronics \& Signals (E\&S); Hardware (Hdwe); Interpersonal Communications (IntpComm); Networks, Web systems, Databases (N,W,D); Physics, Math, Chemistry (Ph, Ma, $\mathrm{Ch}$ ); and Software (Sftwe). 


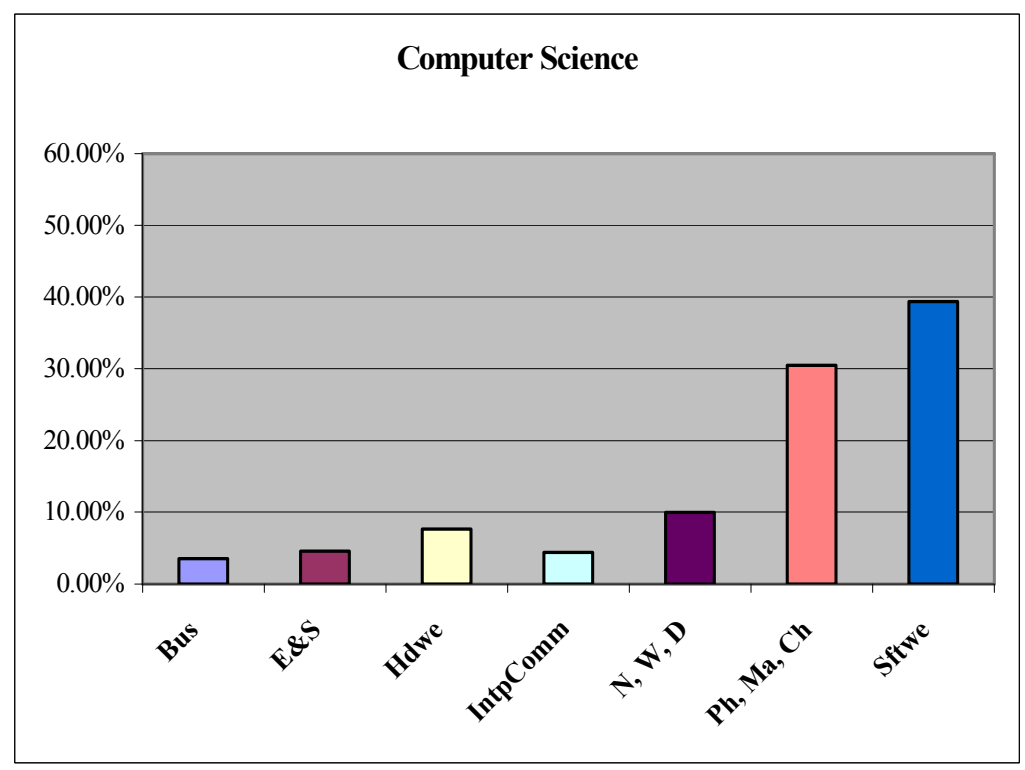

Figure 2: Summary of requirements for Computer Science, organized as in Figure 1. Best for comparing to Figures 3 and 4 below.

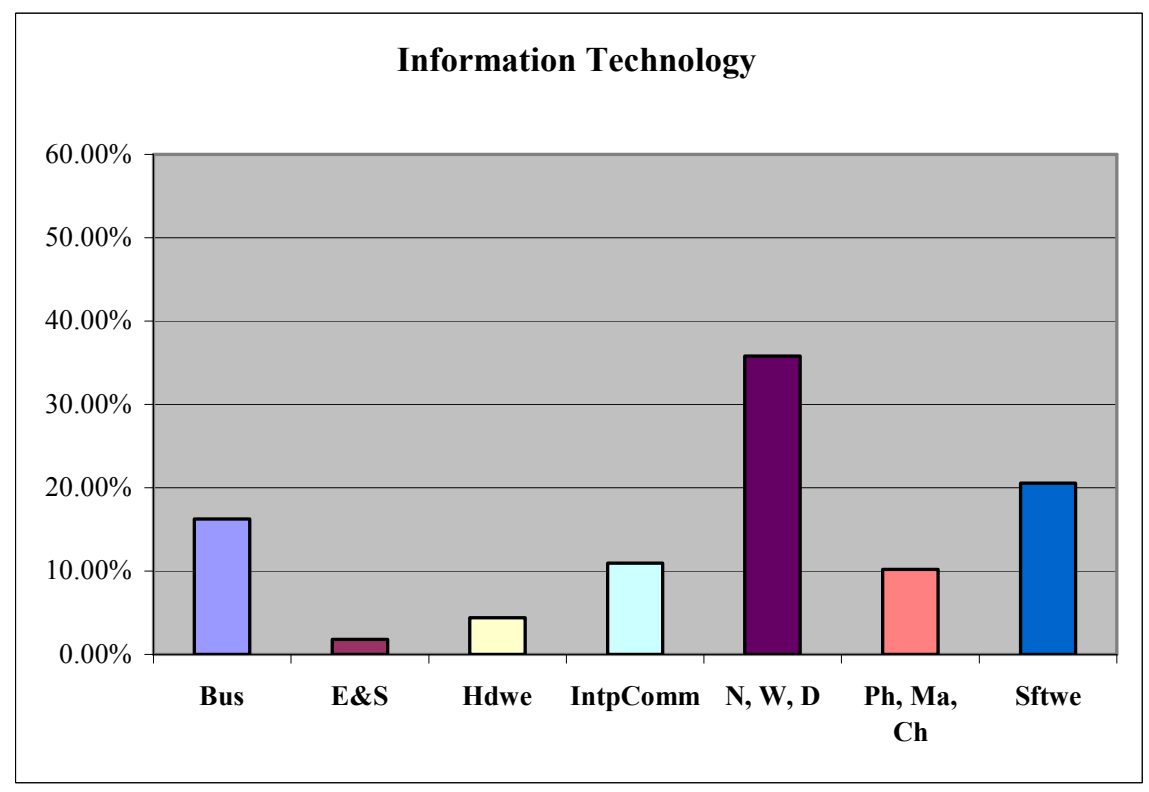

Figure 3: Summary of requirements for Information Technology, organized as in Figure 1. Best for comparing to Figures 2 and 4 above and below. 


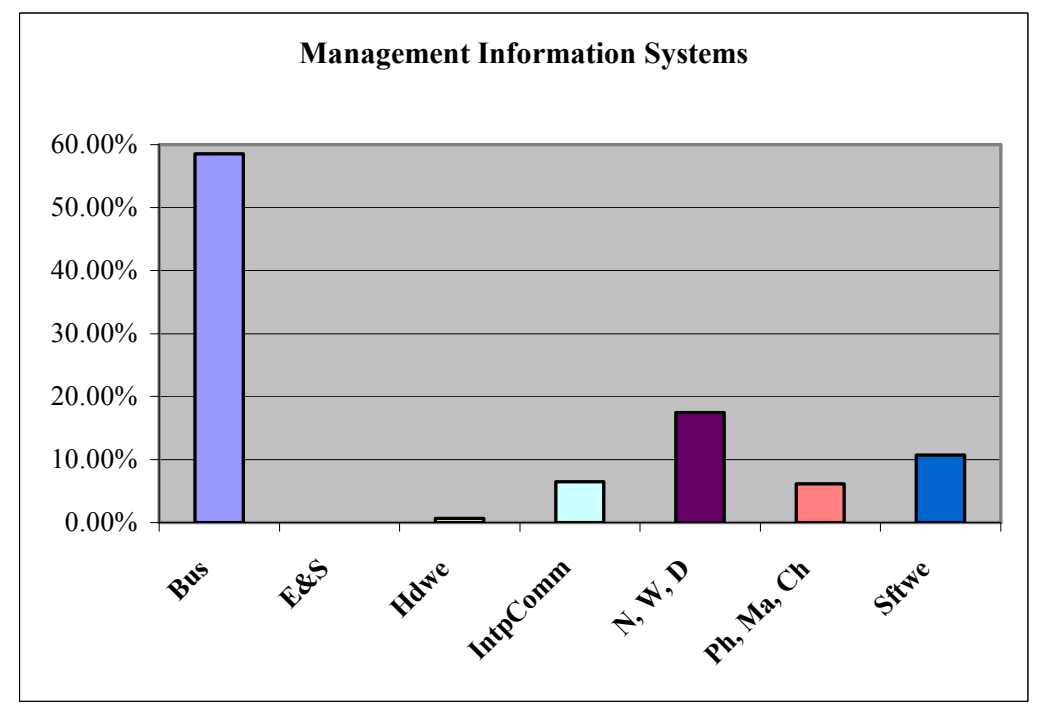

Figure 4: Summary of requirements for Information Systems, organized as in Figure 1. Best for comparing to Figures 2 and 3 above.

multi-volume document, eventually to include volumes in IS, software engineering (SE), computer engineering (CE), and IT. The CS volume of the CC2001 document defines 14 knowledge areas, which are additionally broken down as necessary. In keeping with our agreement to work toward writing the IT volume of the $\mathrm{CC}$, we next endeavored to define the knowledge areas for IT.

After several iterations, the knowledge areas presently defined for IT include the following nine: IT Fundamentals; Programming Fundamentals; Web Systems; Hardware and Operating Systems; Networking; Human-Computer Interaction; Information Management; Social and Professional Issues; and System Integration.

\section{Timeline for IT Curriculum Development}

The 4-year IT curriculum committee formed a writing subcommittee in October of 2003, for the purpose of writing the IT volume of the CC document. As mentioned before, this committee plans to write a document similar to the CS volume of the CC2001 document; this document is over 100 pages in length, including the Appendix. The IT curriculum writing subcommittee has already met once, and has completed a draft of approximately 4 of the 13 chapters of the document. Plans are to hold further writing subcommittee meetings approximately every 2 months, with the goal to have, by June 2004, a draft document ready for posting to the SIGITE website for all to review and comment on. 
Accreditation for IT Programs

As mentioned, the IT accreditation committee was formed at CITC-1 in December 2001. One of the first accreditation issues to be settled was the question of which accreditation agency we would go with. At the time, CS programs were accredited by the Computer Science Accreditation Board (CSAB), and computer engineering and computer engineering technology programs were accredited by the Accreditation Board for Engineering and Technology (ABET). However, this dilemma was soon settled when CSAB opted to discontinue accreditation activities and established that all future accreditations for CS programs would be handled through the Computing Accreditation Commission (CAC) of ABET.

The next question about accreditation dealt with the commission of ABET through which IT would accredit. Some members of SITE wished to affiliate academically with computing programs, and thus seek accreditation through CAC of ABET, while others wished to affiliate academically with engineering technology, and thus seek accreditation through the Technology Accreditation Commission (TAC) of ABET. At CITC-2 this issue was discussed in a plenary session and was then put to a vote. The membership voted decisively to affiliate with computing programs, and to seek accreditation through CAC of ABET.

The next step for the IT accreditation committee was to write the draft accreditation criteria. These criteria were brought in their original draft form to CITC-2, where they were also discussed in a plenary session. Discussion was open and insightful, and several modifications were made. After CITC-2, the accreditation committee made a few other changes as recommended at CITC-2 and the accreditation criteria were posted to the SITE website for all to review and comment (see www.citc.it.rit.edu).

Since the criteria were posted to the above website, a few additional changes have been recommended, discussed, and incorporated as necessary. The most significant change occurred because CAC took the decision to follow the lead of the other accreditation commissions within ABET, most notably EAC, and develop a set of general accreditation criteria for computing disciplines, to be supplemented by discipline specific accreditation criteria for such disciplines as computer science, information systems and information technology. The IT community was invited to participate in the formulation of the general accreditation criteria, and it did indeed do so. The general accreditation criteria have since been approved on first reading by the ABET board of directors and are available for inspection and comment from ABET's web site (www.abet.org/info prgs cac.html). The expectation is that the general accreditation criteria will be piloted by a number of programs in computing, including some IT programs, during the 2004-2005 accreditation cycle. Moreover, the IT community is currently working on IT specific accreditation standards and it hopes to present these for approval to the various bodies early this year.

\section{Conclusion}

The formation of an IT professional society (formerly SITE, now SIGITE), the completion of draft accreditation criteria, and the writing of a draft of the IT volume of the CC document, have 
all taken place in a comparatively short time. Having started in December 2001, the entire process has taken only about $2 \frac{1}{2}$ years so far, and is nearing completion, at least for this initial draft stage.

SIGITE is open to members from any academic programs, and is particularly interested in including members from IT programs across the nation and eventually the world. Participation on any of the committees is open to all SIGITE members.

\section{REFERENCES}

1. Dalkey, N. \& O. Helmer, "The Use of Experts for the Estimation of Bombing Requirements: A Project Delphi Experiment", Santa Monica, CA: Rand Corp., 1951.

2. Brown, B., "Delphi Process: A Methodology Used for the Elicitation of Opinions of Experts", Santa Monica, CA: Rand Corp., 1968.

3. Dalkey, N., "Delphi:, Santa Monica, CA: Rand Corp., 1967.

4. Dalkey, N., "The Delphi Method: An Experimental Study of Group Opinion”, Santa Monica, CA: Rand Corp., 1969.

5. Dalkey, N., et al., "The Delphi Method III: Use of Self Ratings to Improve Group Estimates", Santa Monica, CA: Rand Corp., 1969.

6. Lunt, B.M., et al. An Empirical Comparison of Baccalaureate Programs in Computing. CITC-3 9/02 Rochester, NY.

7. Lunt, B.M., et al. What is the New Discipline of Information Technology? Where Does It Fit? CIEC 2003 2/2003, Tucson, AZ.

\section{APPENDIX}

List of Job Titles

Networking job titles:

Cable Installers; Communications Analyst; Customer Service Coordinator; Hardware Installations Coordinator Hardware Support/Maintenance; Local Area Network Technician; Network Administration; Network Administrator Network Analyst; Network Maintenance and Operations; Network Operations Analyst; Network Specialist; Network Technician; Telecommunications Technician; Wide Area Network Technician

Information Services and Support job titles:

Call Center Support Representative; Computer Operations Technician; Computer Operator; Customer Service Representative; Data Analyst; Database Administrator; Database Analyst; Database Developer; Database Specialist; Help Desk Technician; IS Operator/Analyst; LAN Applications Support Analyst; Lead Customer Service Coordinator; Operations Scheduler; PC Support Specialist; PC System Coordinator; PC Technician; Product Support Engineer; Software Application Specialist; Systems Administrator; Technical Sales Consultant; Technical Support Engineer; Technical Support Representative; Technical Writer

Programming and Software Development:

Database Software Technician; Entry (Junior Level) Programmer; Operating Systems Specialist; Programmer Analyst; Senior Level Programmer; Software Applications Specialist; Software Designer; Software/Application Support; Systems Analyst; Test Specialist

\section{Interactive Media:}

Animator; Audio/Visual Specialist; Graphic Designer; Graphics Technician; Imaging Specialist; Instructional Designer; Interactive Digital Media Specialist; Media Designer; Multi-Media Programmer; Multi-Media Specialist Multimedia Technician; Production Assistant; Project Manager; Quality Assurance Technician; Virtual Reality Designer; Visual Design Consultant; Web Content Designer; Web Designer; Writer

\section{Additions from the Curriculum committee (unclassified)}

Database architect; Computer Analyst; Development Engineer; Engineering Specialist; Member, Technical Staff; Network Analyst; Network Test Engineer; Principal Engineer; Programmer Analyst; Project Engineer; Project Supervisor; Senior Engineer; Software Development Manager; Software Engineer; Software Quality Engineer; Software Test Engineer; Systems Analyst; Systems Engineer; System Support Engineer; System Test Engineer 


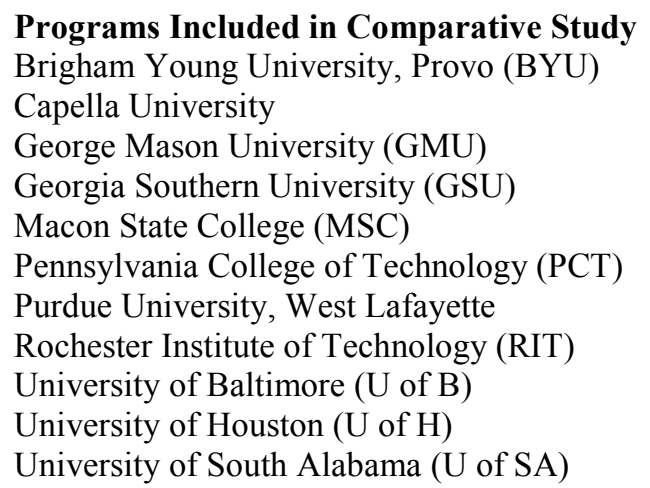

\section{BARRY LUNT}

Barry M. Lunt is an Associate Professor of Information Technology at Brigham Young University in Provo, UT. Dr. Lunt received a B.S. and an M.S. degree in EET from BYU, and a Ph.D. in Occupational and Adult Education from Utah State University in Logan, UT. He has spent seven years in industry as a design engineer. His present research emphases are the physical design of electronic circuits and systems, IT curriculum, and engineering education.

\section{JOSEPH EKSTROM}

Joseph J. Ekstrom (Ph. D. Computer Science, BYU 1992) has been Associate Professor of Information Technology at BYU since 2001. During 30 years of industrial experience he held positions from developer through senior management. His research interests include network and systems management, distributed computing, system modeling and architecture, system development, and IT curriculum and instruction.

\section{SANDRA GORKA}

Sandra Gorka is an Assistant Professor of Information Technology at the Pennsylvania College of Technology (PCT) in Williamsport, Pennsylvania. Dr. Gorka received a B.A. in mathematics from Shippensburg University, and an M.S. degree and Ph.D. in mathematics and topology from the University of Delaware. She has worked for several years as a private consultant. Her present research interests include IT curriculum, pedogogy and education.

\section{REZA KAMALI}

Reza Kamali is an Associate Professor and department head of Information Systems/Information Technology department at Purdue Calumet University, Hammond, IN. Dr. Kamali received a B.A. in Economics from University of Tehran, Iran, an M.S. in Computer Science and an M.S. in Mathematical Sciences, both from University of Arkansas, and a Ph.D. in Mathematics from Drexel University. His present research emphasis is IT curriculum.

\section{EYDIE LAWSON}

Edith A. Lawson is the Department Chair of the Information Technology Department at the Rochester Institute of Technology in Rochester, New York. She completed a BS degree in Economics at Wisconsin State University and an MS in Business and an MS in Computer Science at the Rochester Institute of Technology. Her primary areas of interest are database programming, E-commerce and applied computing education.

\section{JACOB MILLER}

Jacob R. Miller is an Associate Professor of Computer Science at the PCTin Williamsport, Pennsylvania. He earned his B.A. in mathematics at Shippensburg University and his M.S. and Ph.D. degrees at the University of Delaware in mathematics and dynamical systems. He has spent seven years working in industry for IBM in inventory planning and distribution. His present research is in IT education and curriculum as well as network security.

\section{HAN REICHGELT}

Han Reichgelt is associate professor of information technology and acting chair of the department of information technology at Georgia Southern University. He holds first degrees in philosophy and psychology from the University of Nijmegen in the Netherlands and a PhD in Cognitive Science from the University of Edinburgh. His main research interests are information technology and computer science education, e-commerce, and IT and economic development. 